\title{
Seasonal influenza immunization in early infancy?
}

\author{
Maurizio Bonati ${ }^{1 *}$ and Antonio Clavenna ${ }^{2}$
}

Keywords: Influenza vaccines, Vaccination, Newborn, Infant

Seasonal influenza is an important public health and medical challenge. Vaccination against influenza is recognized worldwide as the main strategy for prevention and control. The findings of meta-analyses, however, suggest that efficacy and effectiveness of influenza vaccines, both in people aged 65 years or older [1] and in children, are lower than believed [2]. These findings were recently confirmed, even if mitigated (only) a little, by an additional meta-analysis. This recent study assessed efficacy and effectiveness of licensed influenza vaccines in the USA with sensitive and highly specific diagnostic tests used to confirm influenza [3]. Findings show that in healthy children influenza vaccines have a very variable efficacy (vaccine effects on lab-confirmed influenza) and effectiveness (prevention of influenza-like illness). Available safety data are scant, particularly for inactivated vaccines in younger children [2]. In such a context, when the seasonal periods for influenza arrive, questions concerning who should receive the influenza vaccine are raised among health operators and lay people worldwide. Pediatricians, parents, and caregivers of infants and children in particular, are doubtful as to whether to recommend or accept influenza immunization of children or not [4], also because in children the infection is usually self-limiting without complications, though the risk is higher in those aged less than 6 months [5].

In 2010, the Advisory Committee on Immunization Practices (ACIP) established the first recommendation for a national, universal seasonal influenza vaccination in the USA [6].

Vaccination every year is recommended by ACIP with trivalent inactivated vaccine (TIV) for all individuals aged 6 months or older, or with live attenuated influenza vaccine (LAIV) for healthy, non-pregnant people aged 2-49 years. Up until now only a few countries (i.e.,

\footnotetext{
*Correspondence: mother_child@marionegri.it

'Laboratory for Mother and Child Health, Department of Public Health, Mario Negri Research Institute, Via G. La Masa 19, 20156 Milan, Italy

Full list of author information is available at the end of the article
}

Austria, Canada, and Estonia) universally recommend the seasonal influenza vaccination. The majority of countries continues to apply, for the paediatric population, the World Health Organization recommendations that suggest vaccinating only children older than 6 months of age with certain coexisting conditions (chronic heart or lung diseases, metabolic or renal diseases, chronic neurological conditions, or immunodeficiencies) through strategies that involve an active promotion of the vaccine [7]. Household contacts of those children are unfortunately not considered, although individual member states may consider influenza vaccination programs that target all persons 6 months of age and older if feasible and cost-effective.

This is the public health context, in which national and regional decisions are the result of prevailing evaluations often characterized by a balancing of, and mediation between, evidence based knowledge, available public funds, health system organization, as well as historical legacies and inertia, policy lock-in, and unchecked assumptions about the benefit of influenza vaccines.

Scant data are available concerning the incidence of influenza in the pediatric population. A meta-analysis of 24 epidemiological studies monitoring different influenza seasons estimated an annual incidence in children less than 5 years old of $5.6 \%$ (95\%CI 2.8 to $10.6 \%)$ in the developed countries and of $15.0 \%$ (95\% CI 9.8 to $22.9 \%$ ) in developing countries [5]. The incidence in developed countries decreased to $3.0 \%(0.9,10.0 \%)$ when only study using polymerase chain reaction as diagnostic tool were taken into account [5].

The average annual rate of hospitalization associated with influenza is reported in developed countries as ranging from 0.6 to 2.7 per 1000 children younger than 5 years of age $[8,9]$, whereas the average annual rates of outpatient visits attributable to influenza are 10-250 times as high as hospitalization rates, and increase with age [8].

This wide variability in estimates is attributable to differences in the studies performed. These include study 
year, country, setting, size and characteristics of population surveyed, definition of influenza season, study design and objectives.

Such a weakly defined epidemiological profile coincides with the lack of hard evidence on efficacy and effectiveness of influenza immunization in children because the same limitations are present in clinical trials, with even further variability attributable to laboratory tests, vaccines used, etc.

Public health decisions and recommendations are consequently not only complex in and of themselves, but are also difficult in such a scenario.

Ongoing research in the field (much of which is industry sponsored) is waiting for a new generation of more effective, cross-protective influenza vaccines and is, in the meantime, oriented towards defining the efficacy in children of influenza vaccines that are used in adults. The TIV vaccine has currently been shown an efficacy (prevention of confirmed influenza) of 59\% and an effectiveness (prevention of influenza-like illness) of $36 \%$ in children older than 2 years of age [2], whereas the intranasal LAIV has been shown to have a greater efficacy (69.2-95.6\%) only in children 2-7 years of age, but cannot be used in children under 2 years of age because of an increased risk of hospitalization [10].

At present, children aged 6-72 months are the favorite population of influenza vaccine studies to show a superior protective efficacy of adjuvant TIV vaccines [11].

The question, however, remains. Should infants be vaccinated against seasonal influenza? Currently, this vaccination is not recommended in any country for healthy, preterm, or low birth weight infants, even if they have chronic diseases that are contemplated by immunization strategies for infants older than 6 months. Moreover, it is important to underline that influenza vaccines up to date have not been approved by regulators for use in infants.

Due to the immature or impaired cellular and humoral immune systems and the presence of maternal antibodies at protective levels in babies, in several countries vaccines are routinely recommended from 2 months of age, also for preterm and low birth weight infants $[12,13]$. The only exception is the vaccination against hepatitis B for all at risk newborns, in particular those born to mothers HBsAG positive, who should receive the vaccine within 12-24 hours after birth, regardless of gestational age or birth weight $[12,14]$.

Although the risk of severe influenza infection and the rate of hospitalization are higher in infants during their first 6 months of life than in older infants [8], in particular in those born to mothers who have not been exposed to the virus [15], there are only 4 published studies on inactivated influenza vaccination in infants under 6 months [16-19].
In the first study, 62 infants 3 to 5 months of age with bronchopulmonary dysplasia or congenital heart disease were vaccinated using four different TIV vaccines [16]. In the second study, 42 healthy infants aged 10-22 weeks received two different TIV vaccines [17]. In the third, 126 infants 2-3 months of age were randomized to receive a TIV vaccine either via the intramuscular or intradermal route [18]. The findings of the first two studies demonstrated seroconversion only in the range of 0-55\% against the various vaccine-contained antigens with a suggested age related trend, whereas the extremely high percentage of maternal antibodies at protective levels in the infants in the third study precluded the testing of immunogenicity in this age group (only 4 out of 126 infants had hemagglutination inhibition titer $<40$ against at least one vaccine-covered antigen before vaccination) [18].

In a large randomized placebo controlled trial evaluating the antibody titers in 1304 subjects 6-12 weeks of age, $90.2 \%$ of TIV recipients achieved potential seroprotection to at least one influenza strain following the second vaccine dose [19]. Seroprotection rates differed from 10.9 to $85.6 \%$ among individual vaccine antigens. Safety profiles were similar in the TIV and placebo groups [19].

All these studies were mainly focused on the evaluation of immunogenicity. None of them was designed for evaluating clinical or public health endpoints.

In the past a few studies were performed to evaluate the immunogenicity of LAIV vaccines in infants under 6 months $[2,20,21]$. The rate of seroconversion was similar to that observed with TIV vaccines, but a higher rate of adverse effects was reported with LAIV vaccines in children under 2 years of age [10].

Without evidence suggesting benefit outweights harms at either the individual or societal (public health) level, today, any attempt to suggest immunizing infants less than 6 months of age against seasonal influenza would be off-label, arbitrary and unethical. Off-label use of drugs and vaccines is legal since regulatory agencies do not regulate the practice of medicine but, either way, it should be evidence-based. Public health solutions using current influenza vaccines are difficult to imagine because of the wide methodological differences between the performed studies; the interseasonal variation and the everchanging antigenicity of the influenza virus; the variation in efficacy and effectiveness (risk reduction in populations offered the vaccine) by total vaccine coverage and degree of herd immunity for each season.

However, infants younger than 6 months are also a reservoir for potential child-to-adult transmission and other effective preventive and treatment strategies for these infants alternative to influenza vaccines should be fully evaluated. The high maternal antibody levels 
detected in many infants in the above studies are in agreement with the results of investigations showing that the vaccine is safe and effective in protecting pregnant women and their infants for a few months after birth [22]. 45-65\% of influenza disease in infants is preventable through maternal immunization programmes [23]. In 2005, the WHO was already recommending influenza vaccination for all pregnant women during the influenza season [24]. Although new evidences supports the efficacy and the effectiveness of influenza vaccine administration during pregnancy in exposed women and their newborn babies $[25,26]$, and safety data suggest inactivated vaccines for seasonal influenza are safe in pregnancy $[27,28]$, vaccination is underused in pregnancy [29].

Concerning the passive immunization, or indirect protection, of a newborn, the breast milk-mediated protection against respiratory viruses is well established [30], as the role of brestfeeding in infants infected with influenza virus [31], thus promoting exclusive breastfeeding also against infectious diseases should be kept in mind $[32,33]$. Therefore, while waiting for safe, effective and affordable vaccines for infants, this population can also be protected by limiting their exposure to influenza through both educational interventions (including hand washing) [6,34,35] targeting health care workers [36], family members, caregivers, and all individuals who reside with newborns, in particular ill ones [35]. Moreover, some benefits may be obtained by applying "cocoon" immunization strategies immunizing all individuals who come into contact with infants, as suggested by uncontrolled studies [37].

In conclusion, seasonal influenza is a major public health issue at the extremes of ages and in susceptible groups. Until an effective influenza vaccine is achievable, more evidence about both efficacy of flu immunization in early infants and alternative interventions to influenza vaccination is available, and preventive strategies implemented, it would be more important to improve the coverage in higher risk children than to enlarge the immunization age range of healthy children.

\section{Abbreviations}

ACIP: Advisory Committee on Immunization Practices; LAIV: Live attenuated influenza vaccine; TIV: Trivalent inactivated vaccine.

\section{Competing interest}

Both authors declare that about competing interest have nothing to declare.

\section{Authors' contributions}

MB, Head of Public Health Department and of the Laboratory of Mother and Child Health at Mario Negri Research Institute of Milan, was responsible for the drafting, revising, and submitting of the commentary; AC, Head of Pharmacoepidemiology Unit at Mario Negri Research Institute of Milan reviewed and revised the text for important intellectual content. Both authors read and approved the final manuscript.

\section{Author details}

'Laboratory for Mother and Child Health, Department of Public Health, Mario Negri Research Institute, Via G. La Masa 19, 20156 Milan, Italy.

${ }^{2}$ Pharmacoepidemiology Unit, Mario Negri Research Institute of Milan, Milan, Italy.

Received: 21 March 2012 Accepted: 10 October 2012

Published: 15 October 2012

\section{References}

1. Jefferson T, Di Pietrantonj C, Al-Ansary LA, Ferroni E, Thorning S, Thomas RE: Vaccines for preventing influenza in the elderly. Cochrane Database Syst Rev 2010, 2:CD004876.

2. Jefferson T, Rivetti A, Harnden A, Di Pietrantonj C, Demicheli V: Vaccines for preventing influenza in healthy children. Cochrane Database Syst Rev 2008, 2:CD004879.

3. Osterholm MT, Kelley NS, Sommer A, Belongia EA: Efficacy and effectiveness of influenza vaccines: a systematic review and metaanalysis. Lancet Infections Diseases 2012, 12:36-44.

4. Flood EM, Rousculp MD, Ryan KJ, Beusterien KM, Divino VM, Toback SL, Sasané M, Block SL, Hall MC, Mahadevia PJ: Parents' decision-making regarding vaccinatingtheir children against influenza: A web-based survey. Clin Ther 2010, 32:1448-1467.

5. Nair H, Brooks WA, Katz M, Roca A, Berkley JA, Madhi AS, Simmerman JM, Gordon A, Sato M, Howie S, Krishnan A, Ope M, Lindblade KA, CarosoneLink P, Lucero M, Ochieng W, Kamimoto L, Dueger E, Bhat N, Vong S, Theodoratou E, Chittaganpitch M, Chimah O, Balmaseda A, Buchy P, Harris E, Evans V, Katayase M, Gaur B, O'Callaghan-Gardo C, et al: Global burden of respiratory infections due to seasonal influenza in young children: a systematic review and meta-analysis. Lancet 2011, 378:1917-1930.

6. Centers for Disease Control and Prevention: Prevention and Control of Influenza with Vaccines: Recommendations of the Advisory Committee on Immunization Practices (ACIP), 2010. MMWR 2010, 59:RR-8 http://www. cdc.gov/mmwr/preview/mmwrhtml/rr5908a1.htm.

7. World Health Organization: Influenza (Seasonal). Fact sheet N²11. 2009. http://www.who.int/mediacentre/factsheets/fs211/en/.

8. Poehling KA, Edwards KM, Weinberg GA, Szilagyi $P$, Staat MA, Iwane MK Bridges CB, Grijalva CG, Zhu Y, Bernstein DI, Herrera G, Erdman D, Hall CB, Seither R, Griffin MR: for the New Vaccine Surveillance Network. The underrecognized burden of influenza in young children. $N$ Engl J Med 2006, 355:31-40.

9. Esposito S, Cantarutti L, Molteni CG, Daleno C, Scala A, Tagliabue C, Pelucchi C, Giaquinto C, Principi N: Clinical manifestations and socio-economic impact of influenza among healthy children in the community. J Infect 2011, 62:379-387.

10. Rhorer J, Ambrose CS, Dickinson S, Hamilton H, Oleka NA, Malinoski FJ, Wittes J: Efficacy of live attenuated influenza vaccine in children: a meta-analysis of nine randomized clinical trials. Vaccine 2009, 27:1101-1110.

11. Vesikari T, Knuf M, Wutzler P, Karvonen A, Kieninger-Baum D, Schmitt HJ, Baehner F, Borkowski A, Tsai TF, Clemens R: Oil-in-water emulsion adjuvant with influenza vaccine in young children. N Engl J Med 2011, 365:1406-1416.

12. Saari TN: American Academy of Pediatrics Committee on Infectious Diseases. Immunization of preterm and low birth weight infants. Pediatrics 2003, 112:193-198.

13. Gaudelus J, Lefèvre-Akriche S, Roumegoux C, Bolie S, Belasco C, Letamendia-Richard E, Lachassinne É: Vaccination du prematuré. Arch Pediatr 2007, 14:S24-S30

14. World Health Organization: Hepatitis B. http://www.who.int/csr/disease/ hepatitis/whocdscsrlyo20022/en/index4.html.

15. Bhat N, Wrigth JG, Broder KR, Murray EL, Greenberg ME, Glover MJ, Likos AM, Posey DL, Klimov A, Lindstrom SE, Balish A, Medina M, Wallis TR, Guarner J, Paddock CD, Shieh WJ, Zaki SR, Sejvar JJ, Shay DK, Harper SA, Cox NJ, Fukuda K, Uyeki TM: for the Influenza Special Investigations Team. Influenza-associated deaths among children in the United States, 2003-2004. N Engl J Med 2005, 353:2559-2567.

16. Groothuis JR, Levin MJ, Rabalais GP, Meiklejohn G, Lauer BA: Immunization of high-risk infants younger than 18 months of age with split-product influenza vaccine. Pediatrics 1991, 87:823-828. 
17. Halasa NB, Gerber MA, Chen Q, Wright PF, Edwards KM: Safety and immunogenicity of trivalent inactivated influenza vaccine in infants. $J$ Infect Dis 2008, 197:1448-1454.

18. Chiu SS, Chan KH, Tu W, Lau YL, Peiris JS: Immunogenicity and safety of intradermal versus intramuscular route of influenza immunization in infants less than 6 months of age: a randomized controlled trial. Vaccine 2009, 27:4834-4839.

19. Englund JA, Walter E, Black S, Blatter M, Nyberg J, Ruben FL, Decker MD: GRC28 Study Team. Safety and immunogenicity of trivalent inactivated influenza vaccine in infants: a randomized double-blind placebocontrolled study. Pediatr Infect Dis J 2010, 29:105-110.

20. Gruber WC, Darden PM, Still JG, Lohr J, Reed G, Wright PF: Evaluation of bivalent live attenuated influenza $A$ vaccines in children 2 months to 3 years of age: safety, immunogenicity and dose-response. Vaccine 1997, 15:1379-1384.

21. Clements ML, Makhene MK, Karron RA, Murphy BR, Steinhoff MC, Subbarao K, Wilson MH, Wright PF: Effective immunization with live attenuated influenza $A$ virus can be achieved in early infancy. Pediatric Care Center J Infect Dis 1996, 173:44-51.

22. Blanchard-Rohner $G$, Siegrist CA: Vaccination during pregnancy to protect infants against influenza: Why and why not? Vaccine 2011, 29:7542-7550.

23. Ortiz JR, Englund JA, Neuzil KM: Influenza vaccine for pregnant women in resource-constrained countries: a review of the evidence to inform policy decisions. Vaccine 2011, 29:4439-4452.

24. World Health Organization: Influenza vaccines. Wkly Epidemiol Rec 2005, 33:279-287. http://www.who.int/wer/2005/wer8033.pdf.

25. Zaman K, Roy E, Arifeen SE, Rahman M, Ragib R, Wilson E, Omer SB, Shahid NS, Breiman RF, Steinhoff MC: Effectiveness of maternal influenza immunization in mothers and infants. N Engl J Med 2008, 359:1555-64.

26. Steinhoff MC, Omer SB, Roy E, El Arifeen S, Raqib R, Dodd C, Breiman RF, Zaman K: Neonatal outcomes after influenza immunization during pregnancy: a randomized controlled trial. CMAJ 2012, 184:645-653.

27. Moro PL, Broder K, Zheteyeva Y, Walton K, Rohan P, Sutherland A, Guh A, Haber $P$, DeStefano F, Vellozzi C: dverse events in pregnant women following administration of trivalent inactivated influenza vaccine and live attenuated influenza vaccine in the Vaccine Adverse Event Reporting System, 1990-2009. Am J Obstet Gynecol 2011, 204:146.e1-146.e7

28. Tamma PD, Ault KA, del Rio C, Steinhoff MC, Halsey NA, Omer SB: Safety of influenza vaccination during pregnancy. Am J Obstet Gynecol 2009 201:547-552.

29. Centers for Disease Control and Prevention: Influenza vaccination coverage among pregnant women-United States, 2010-11 influenza season. MMWR 2011, 60:1078-1082.

30. Lopez-Alarcon M, Villalpando S, Fajardo A: Breastfeeding lowers the frequency and duration of acute respiratory infection and diarrhea in infants under six months of age. J Nutr 1997, 127:436-443.

31. Melendi GA, Coviello S, Bhat N, Zea-Hernandez J, Ferolla FM, Polack FP. Breastfeeding is associated with the production of type i interferon in infants infected with influenza virus Acta Paediatrica. International Journal of Paediatrics 2010, 99:1517-1521.

32. Lawrence RM, Pane CA: Human Breast Milk: Current Concepts of Immunology and Infectious Diseases. Curr Probl Pediatr Adolesc Health Care 2007, 37:7-36.

33. Dòrea JG: Breastfeeding is an essential complement to vaccination. Acto Paediatr 2009, 98:1244-1250.

34. Jefferson T, Del Mar CB, Dooley L, Ferroni E, Al-Ansary LA, Bawazeer GA, van Driel ML, Nair S, Jones MA, Thorning S, Conly JM: Physical interventions to interrupt or reduce the spread of respiratory viruses. Cochrane Database Syst Rev 2011, 7:CD006207.

35. Godoy P, Castilla J, Delgado-Rodríguez M, Martín V, Soldevila N, Alonso J, Astray J, Baricot M, Cantón R, Castro A, González-Candelas F, Mayoral JM Quintana JM, Pumarola T, Tamames S, Domínguez A, Azor E, Carrillo J, Moyano R, Navarro JA, Vázquez M, Zafra F, Bueno MA, Gómez ML, Mariscal M, Martínez B, Quesada JP, Sillero M, Carnero M, Fernández-Crehuet J, et al: Effectiveness of hand hygiene and provision of information in preventing influenza cases requiring hospitalization. Prev Med 2012, 54:434-439.

36. Nair H, Holmes A, Rudan I, Car J: Influenza vaccination in healthcare professionals. BMJ 2012, 344:e2217.

37. Burke BL Jr, Nesmith CC, Ott RE, Hedrick ML: Through with the flu: how free family and caregiver immunization protects sick neonates. Clin Pediatr (Phila) 2010, 49:20-23.

doi:10.1186/1471-2458-12-873

Cite this article as: Bonati and Clavenna: Seasonal influenza

immunization in early infancy? BMC Public Health 2012 12:873.

\section{Submit your next manuscript to BioMed Central and take full advantage of:}

- Convenient online submission

- Thorough peer review

- No space constraints or color figure charges

- Immediate publication on acceptance

- Inclusion in PubMed, CAS, Scopus and Google Scholar

- Research which is freely available for redistribution

Submit your manuscript at www.biomedcentral.com/submit
C) BioMed Central 